\title{
Health Resources and Well-Being in Optimal Aging: The Mediating Role of Selection, Optimization, and Compensation Strategies
}

\author{
Cheng-Hua Wang ${ }^{1}$ and Fu-Fei Tsai ${ }^{2, *}$ \\ 1 Department of Business Administration, College of Management, Chang Jung Christian University, \\ Tainan 711301, Taiwan; huager@mail.cjcu.edu.tw \\ 2 Ph.D. Program in Business and Operations Management, College of Management, Chang Jung Christian \\ University, Tainan 711301, Taiwan \\ * Correspondence: tsaifufei@gmail.com
}

Citation: Wang, C.-H.; Tsai, F.-F. Health Resources and Well-Being in Optimal Aging: The Mediating Role of Selection, Optimization, and Compensation Strategies. Sustainability 2021, 13, 9224. https://doi.org/10.3390/su13169224

Academic Editor: Mihajlo

(Michael) Jakovljevic

Received: 12 July 2021

Accepted: 15 August 2021

Published: 17 August 2021

Publisher's Note: MDPI stays neutral with regard to jurisdictional claims in published maps and institutional affiliations.

Copyright: (c) 2021 by the authors. Licensee MDPI, Basel, Switzerland. This article is an open access article distributed under the terms and conditions of the Creative Commons Attribution (CC BY) license (https:/ / creativecommons.org/licenses/by/ $4.0 /)$.

\begin{abstract}
Aging and health issues continue to receive attention, especially under the global health challenge of achieving the Sustainable Development Goals. It is important to understand how people adapt their lifespan development to face the gains and losses of resources. The purpose of this study was to test the relationships between health resources, selection, optimization, and compensation (SOC) strategies and well-being with aging; to examine the impact of SOC strategies on health resources and well-being, and the link between health resources and well-being. Using structural equation modeling to analyze our hypotheses, a sample survey of 372 adults was conducted. The results showed that health resources were positively and significantly related to SOC and well-being. SOC strategies were positively and significantly related to well-being and SOC strategies partially mediated the link between health resources and well-being. The findings contribute to the literature by establishing a model and providing practical implications for individual behavior, as well as better understanding of the theoretical and practical implications of aging and health. A friendly community and organization may help people's well-being in terms of physiology, psychology, society, and environment.
\end{abstract}

Keywords: health; well-being; selection, optimization, and compensation (SOC); resources; aging

\section{Introduction}

Achieving health and well-being has become an issue of growing importance, particularly with the recent coronavirus disease 2019 (COVID-19) pandemic that has spread globally [1,2]. Since the outbreak in December 2019 last year, there have been many confirmed cases and deaths from COVID-19 in various countries and regions. We live in increasingly interdependent and global environments and the COVID-19 pandemic presents countries with major political, economic, societal, cultural, educational, transportation, and public health challenges [3]. People are the most important resources in the world, in countries, organizations and families, just as health is the most important for individuals [4]. Health resources are defined as the functions of daily activities completed due to physical and mental health. That is to say, in order to prevent people's health from being threatened, people may be forced to suspend work and adjust to interact with family and friends. These changes also cause personal psychological burdens, an increase in social isolation, and a decrease in interpersonal interactions. As a result, such shocks will ultimately affect people's satisfaction with the environment, society, politics, economy, life, and even well-being.

In addition to the COVID-19 pandemic, many other public health issues still need to be resolved; especially for those with poor immunity and diseases after middle age, or the elderly, who are more threatened [5]. Over the last few decades, population aging 
issues have increased due to medical technology development, economic growth, social improvement [6], family structure change [7], increased rates of chronic disease [8], high life expectancies, low fertility rates, high female education, and increased rates of employment for women [9]. As such, when the labor force is insufficient, people must postpone retirement [10], even if they are unwell due to physical or psychological factors. Good health and well-being are one of the 17 sustainable development goals (SDGs), which the United Nations General Assembly adopted for "the 2030 Agenda" in September 2015. In other words, we need an integrated resource and strategy perspective to properly address the challenge posed by survival, especially in uncertain environments.

Despite medical technology constantly improving, people live still under many uncertainties and pressures due to the threat of global emerging diseases (e.g., the recent COVID-19 pandemic) and aging trends [11]. Health and well-being are the most precious resources and have universal value [12]. Well-being is defined as subjective evaluation of one's satisfaction with life in physiology, psychology, society, and environment. However, under the influence of culture, personal value, life experience, knowledge, and other factors, it is not known how to perceive health and well-being, and selection, optimization, and compensation (SOC) strategies used after middle age and in older adults [13]. Studies are needed to verify whether people with abundant health resources are more likely to use SOC strategies to feel high levels of well-being or whether this has no effect on improving well-being [14,15], whether people with insufficient health resources can still perceive wellbeing [16], whether people may apply strategies and risk management to reduce losses and maximize the use of resources [17], and whether older adults have a stronger need to use SOC strategies than middle-aged adults [18]. Moreover, Hobfoll et al. [19] suggested testing the conservation of resources (COR) theory and the application of resources in health through intervention. Halbesleben et al. [20] reported that COR theory should integrate different theories to complete the interpretation of resource loss and acquisition. While the literature [21,22] on SOC use treats it as moderator, this research intends to test the model by using SOC strategies as mediator between health resources and well-being.

The purpose of this study was to determine why individuals maintain and prolong health resources to achieve their well-being, and how they reach their personal goals when they continue to face multiple challenges with age such as the gain and loss of the resources of physical function, mental health, social relationships, and roles, by analyzing the effects of health resources on well-being and SOC strategies, and the effects of SOC strategies on well-being. This study also aimed to examine to what extent SOC strategies act as a possible mediator of the effect between resources and well-being.

\subsection{Health Resources, Well-Being and SOC Strategies}

The past years have seen a strong interest in aging. Based on the coping, appraisal, resilience, and aging (CARA) model by Aldwin and Igarashi [23], individuals can develop generalized resilience resources through the process of stress appraisals, coping strategies, and coping efficacy. Resources can also help others in individual, family, community, and sociocultural contexts [24]. In other words, optimal aging is influenced by individual resources, barriers, strengths, and vulnerabilities such as health, well-being, and purpose in life. During the aging process, the greatest threat to health-related status comes from cancer and chronic illnesses, especially if they are not carefully managed. Personal health plays a much greater role in future lifespan and later life satisfaction [25]. According to Erikson's (1982) theory of human development in late life, the task is to review life and ego integrity [26]. By recalling the challenge of coping with problems, individuals develop a sense of purpose or meaning, even though physical decline occurs for all [27].

Based on COR theory, Hobfoll [28] proposed the basic tenet of conservation of resources, where people strive to retain, protect, and build resources. The principles of COR theory were summarized into the following elements: primacy of loss principle, resource investment principle, gain paradox principle, and desperation principle [19]. People lose resources, which is likely to result in distress and potentially harmful stress [29]. When 
people gain resources, this brings about eustress (well-being) in emotional, psychological, and physical areas [30]. With the aging process, loss events occur and cannot be avoided, especially health decline [31]. These loss events involve retirement, being fired, disease, and support system blocks. For instance, an individual who experienced a sad bereavement suffered the loss of a loved family member, economic stability, status, life quality and conditions. On the other hand, they could gain resources when they used strategies to change the conditions and increase power, skills, finances, social status, and physical and mental health [32]. Therefore, loss and access to resources can lead to different lifestyles.

SOC theory by Baltes and Baltes (1990) was applied to a set of strategies to counteract resource loss with aging, even though aging may not affect all human beings equally [21]. Researchers have found that SOC strategies may increase resources [33], and help maintain function in the face of challenges [34]. Individuals used the SOC strategies to adapt to changes in development and aging [35]. SOC theory presumes four strategies that include elective selection, loss-based selection, optimization, and compensation [13]. For example, loss-based selection was in response to loss of internal or external resources, to reconstruct individual goal priority [36]. SOC strategies facilitated resources to meet individual situations [37]. For example, people may decide to focus on an important project instead of attending a dinner party (elective selection). People with physical health problems may focus on coordinating the work of their team instead of doing the heavy physical work (loss-based selection). People may participate in training to improve their leadership skills (optimization). Older people may compensate for a loss of physical strength by asking others for help (compensation) [22]. Overall, based on COR theory and SOC theory, personal health resources are expected to relate to SOC strategies and well-being. People can use SOC strategies to deal with physical losses, thereby retaining, maintaining, acquiring, and creating resources to achieve physiological, psychological, social, and environmental well-being.

\subsection{Health Resources and Well-Being}

Health and well-being are commonly and centrally valued resources among people [38]. Halbesleben et al. [20] suggested that "Individuals will engage in behaviors that avoid resource losses since loss can have such a profound negative impact on well-being". In fact, health resources play an important role in relation to individual, family, organization, national competitive strength, and well-being. Based on COR theory, principle 1 states "Resource loss is disproportionately more salient than resource gain", principle 2 states "People must invest resources in order to protect against resource loss, recover from losses, and gain resources", and principle 3 states "Resource gain increases in salience in the context of resource loss" [19]. In other words, resource losses in health (physical function, mental function, role, and social relations) are not only more powerful than resource gains in magnitude, but also tend to have an impact on people (physiological, psychological, social, and environmental well-being).

For instance, people who experience serious illness and lose significant health resources strive to recover health and gain resources of great value, which has a profound effect on survival as well as well-being. Ngamaba et al. [39] reviewed 29 studies and found the effect of health status and well-being was moderate, statistically significant, and positive. In addition, Sun et al. [40] found that there was a strong positive correlation between health and well-being, and this effect still existed after controlling for age, gender, region, and socioeconomics. Furthermore, Steptoe [41] summarized the epidemiological evidence for the relationship between health-related mortality and morbidity and happiness. Based on the reasoning above, we hypothesize:

Hypothesis $\mathbf{1}(\mathrm{H1})$. Health resources are positively related to well-being. 


\subsection{Health Resources and SOC Strategies}

Weber et al. [42] studied whether SOC strategies ease health-related loss of individual resources with age. Moreover, a systematic review by Moghimi et al. [22] explained that, compared with younger workers, older workers with physical decline should use more SOC strategies to retain function [43]. Use of lower SOC strategies was significantly related to poor health, such as depression [44]. Therefore, we expect that individuals with higher health resources will be better at carrying out physical and mental functions specified for roles and actions, which will lead to higher SOC strategies to deal with.

Hypothesis 2 (H2). Health resources are positively related to SOC strategies.

\subsection{SOC Strategies and Well-Being}

Zhang and Radhakrishnan [17] reviewed 19 articles on the use and effect of SOC in patients with chronic diseases and found that SOC can improve symptoms and bring about subjective well-being. In addition, researchers have proved that using SOC strategies predicts well-being [33]. Despite the decline in physical function, the elderly who operated at a high SOC had a higher well-being, while the elderly with a low SOC had a lower well-being despite higher physical function [13]. Therefore, we expect that people who use better SOC strategies will have higher well-being than others.

Hypothesis 3 (H3). SOC strategies are positively related to well-being.

\subsection{SOC Strategies as Mediator between Health Resources and Well-Being}

Using SOC is one of the resources and also a coping strategy for individuals. SOC strategies are related to health resources and well-being [19,45]. A review by Hobfoll et al. [19] indicated that similar to COR theory, SOC theory "focused on gain and loss of resources and the inevitable loss of resources that accompanies aging-which, in turn, demands a realignment of available resources to compensate for failing ones" [46]. Specially, principle 2 of COR theory which is resource investment, where people must invest resources in order to protect against resource loss, recover from losses, and gain resources [19]. Resource investment has been examined in the context of coping, where several studies have suggested that coping implicates resource investment to restrict resource depletion in the future [20]. For instance, Sottimano et al. [33] proposed that SOC strategies could assist older employees to deal with health-related decline due to age, and SOC training and promotion used as interventions might help administrative employees maintain their ability to work.

They found also that the relationship between job control and work ability was mediated by SOC strategies. Some researchers found that people possess different resources to cope with everyday life and this is very important for well-being $[47,48]$. Personal resources and engaging in successful coping strategies have an influence on well-being [43]. A systematic review by Moghimi et al. [22] showed that the use of SOC strategies could mediate the relationships between person and contextual antecedents (subjective physical health, age, emotional intelligence, job demands), and occupational well-being outcomes. As such, the SOC theory could be applied to explain the coping process of resource investment, especially, for example, where individuals endure inevitable physical health decline and have to find extra means to sustain themselves. Further, considering that we expect health resources to relate to SOC strategies, which in turn influences well-being, we propose the following:

Hypothesis 4 (H4). The positive relationship between health resources and well-being is mediated by SOC strategies. 


\section{Materials and Methods}

\subsection{Participants and Procedure}

Participants were recruited from middle aged and older adults (age $\geq 45$ years older). A sample of 384 community-dwelling Taiwanese adults was collected for the self-reported paper and web-based questionnaire. They came from various occupations, and communities. Consent was gained from all participants in this study. Anonymity and confidentiality standards were assured for them. After the data collection, some responses were judged to be invalid due to missing data. Twelve responses were invalid and removed from the sample, leaving 372 questionnaires that were used in the statistical analysis.

Demographic characteristics of the 372 respondents included age ( $36.3 \%$ aged $45-54$ years, $36.3 \%$ aged $55-64$ years, and $27.4 \%$ older than 65 years) and gender $(52.2 \%$ female and $47.8 \%$ male). Among them, $78.5 \%$ had marriage/partnership status, and $85.5 \%$ had children. Approximately half $(49.7 \%)$ of the respondents had a college degree, while more than a quarter $(28.8 \%)$ had a graduate degree. Most $(63.7 \%)$ were engaged in full-time work, more than a quarter $(29.6 \%)$ were retired, and a few $(6.7 \%)$ were unemployed. More than three-quarters $(76.9 \%)$ had religious beliefs.

\subsection{Measurements}

The questionnaire included three parts; health resources, well-being, and SOC strategies, and used a five-point Likert scale ranging from 1 (very little) to 5 (very much). The items in the questionnaire are listed in Appendix A.

Health resources were measured with the revised 36-Item Short Form Health Survey questionnaire (SF-36). Good health related status was one of the individual resources. The SF-36 is a very popular instrument for evaluating health-related surveys [49,50]. It measures eight constructs, including physical function, role physical, bodily pain, general health, mental health, role emotional, social functioning, and vitality. In addition, the SF12 was developed as a shorter alternative to the SF-36, using 12 items instead of 36 items. Health resources are defined as the functions of daily activities completed due to physical and mental health $[49,50]$. Physical function refers to the state of general health, completing daily activities, and body pain. Mental function refers to the state of feeling emotions. Role refers to the role functions related to work and daily regular activities as a result of physical or any emotional problems. Social relations refer to social activities with others. Therefore, health resources were evaluated by the questionnaire, including 11 items (Cronbach's $\alpha=0.88$, see in Table 1 ) and four dimensions (physical function 3 items, mental function 3 items, role 3 items and social relations 2 items).

Table 1. Confirmatory Factor Analysis for the Measurement Model.

\begin{tabular}{|c|c|c|c|c|c|c|c|c|}
\hline Dimension & Code & Sub-Dimension & Items & SFL (Max-Min) & t (Max-Min) & $\alpha$ & $\mathrm{CR}$ & AVE \\
\hline \multirow{5}{*}{$\begin{array}{l}\text { Health } \\
\text { resources }\end{array}$} & R1 & Physical function & 3 & $0.74-0.68$ & $15.13-13.71$ & 0.76 & 0.76 & 0.52 \\
\hline & $\mathrm{R} 2$ & Mental function & 3 & $0.76-0.69$ & $15.03-13.35$ & 0.76 & 0.76 & 0.51 \\
\hline & R3 & Role & 3 & $0.79-0.56$ & $16.83-10.99$ & 0.75 & 0.76 & 0.51 \\
\hline & $\mathrm{R} 4$ & Social relations & 2 & $0.92-0.87$ & 21.78-20.09 & 0.89 & 0.89 & 0.81 \\
\hline & & & 11 & & & 0.88 & 0.93 & 0.56 \\
\hline \multirow{5}{*}{ SOC } & S1 & Elective selection & 2 & $0.81-0.73$ & $12.60-11.80$ & 0.74 & 0.74 & 0.59 \\
\hline & $\mathrm{S} 2$ & Loss-selection & 2 & $0.73-0.61$ & $7.00-6.65$ & 0.61 & 0.62 & 0.45 \\
\hline & S3 & Optimization & 2 & $0.76-0.74$ & $14.93-14.65$ & 0.72 & 0.72 & 0.56 \\
\hline & $\mathrm{S} 4$ & Compensation & 3 & $0.76-0.55$ & $15.07-10.09$ & 0.70 & 0.71 & 0.45 \\
\hline & & & 9 & & & 0.75 & 0.90 & 0.51 \\
\hline \multirow{5}{*}{ Well-being } & W1 & Physiology & 3 & $0.79-0.64$ & $16.72-12.76$ & 0.76 & 0.77 & 0.53 \\
\hline & W2 & Psychology & 3 & $0.77-0.66$ & $16.21-13.11$ & 0.75 & 0.77 & 0.53 \\
\hline & W3 & Society & 3 & $0.80-0.71$ & $16.95-14.39$ & 0.79 & 0.80 & 0.57 \\
\hline & W4 & Environment & 2 & $0.81-0.63$ & $12.97-10.79$ & 0.66 & 0.68 & 0.52 \\
\hline & & & 11 & & & 0.87 & 0.93 & 0.55 \\
\hline Total & & & 31 & & & 0.90 & & \\
\hline
\end{tabular}

$\mathrm{SFL}=$ standardized factor loading; $\mathrm{t}=\mathrm{t}$ value; $\alpha$ = Cronbach's $\alpha$ coefficient; $\mathrm{CR}=$ composite reliability; AVE = average variance extracted. 
Well-being was measured and modified with the 28-item WHOQOL-BREF Taiwan version [51]. WHOQOL-BREF [52] is a very popular instrument for application. In this study, well-being is defined as subjective evaluation of one's satisfaction with life in physiology, psychology, society, and environment [51,52]. Physiology refers to the subjective sense of physiological satisfaction such as health, sleep, and daily living activities. Psychology refers to the subjective feelings of enjoying life, having meaning in life, blue mood, despair, anxiety, and depression. Society refers to the subjective feelings of social satisfaction such as interpersonal relationships, support from friends, and respect. Environment refers to people's subjective feelings about the convenience of daily life, the conditions of the place of residence, and other environmental satisfaction [51,52]. Well-being was evaluated by 11 items (Cronbach's $\alpha=0.87$, see Table 1 ) and divided into four dimensions (physiology 3 items, psychology 3 items, society 3 items and environment 2 items).

SOC strategies were measured with a 9-item and 4-component questionnaire, which modified the 12-item SOC. This original version of the 12-item SOC questionnaire developed by Baltes et al. (1999) was utilized [21]. The SOC scale included four dimensions (elective selection, loss-based selection, optimization, and compensation), with three items per dimension. However, the following modified scale was used in previous research as well $[53,54]$. SOC strategies are defined as "four distinct action regulation strategies that people may use to deal with situations characterized by high demands and limited resources: elective selection, loss-based selection, optimization, and compensation" [22]. Elective selection refers to "the extent to which individuals set and prioritize goals to achieve a desired state" [22]. Loss-based selection refers to "disengaging from unattainable goals, selecting new goals, and reorganizing goal priorities in the face of resource losses" [22]. Optimization refers to "allocating personal resources such as time, effort, and knowledge to attain goals" [22]. Compensation refers to "the acquisition and use of new internal and external resources, as well as the re-activation of unused resources, to achieve a goal when previously used resources are no longer available" [22]. In this study, we revised it from 12 items to 9 items, and calculated all individual items of the four components to indicate overall use of SOC strategies (Cronbach's $\alpha=0.75$, see in Table 1). The SOC strategies questionnaire included elective selection ( 2 items), loss-based selection (2 items), optimization (2 items), and compensation (3 items).

\subsection{Statistical Analysis}

Structural Equation Modeling (SEM) was used to analyze two parts of the measurement model showing the relations between latent variables and their indicators, and the structural model showing potential causal dependencies between endogenous and exogenous variables (see Figure 1 Research model). Maximum likelihood (ML) estimation was used in the SEM models. We accounted for the categorical indicator variables, that is, by calculating the comprehensive score (average) of five types of Likert type items to create Likert scale items. Model estimation was conducted using IBM SPSS Amos Version 24. Confirmatory Factor Analysis (CFA) was conducted to examine whether items in the health resources, SOC strategies, and well-being measures captured the three distinctive constructs. Cronbach's $\alpha$ was used to measure the degree of consistency between items within the same construct. CFA was used to test reliability and convergent validity and discriminate validity of the measurement model. Composite Reliability (CR) and Average Variance Extracted (AVE) were calculated to examine reliability and internal validity. Convergent validity was used to measure the correlation between two observed variables (indicators) of the construct. There are two criteria for convergence validity, in that the standardized factor load of each indicator is greater than 0.50 and significant; and Average Variance Extracted (AVE) is greater than 0.50. The square root of the AVE value of each construct is more significant than the correlation coefficient between other constructs, that is, these constructs have discriminative validity. 


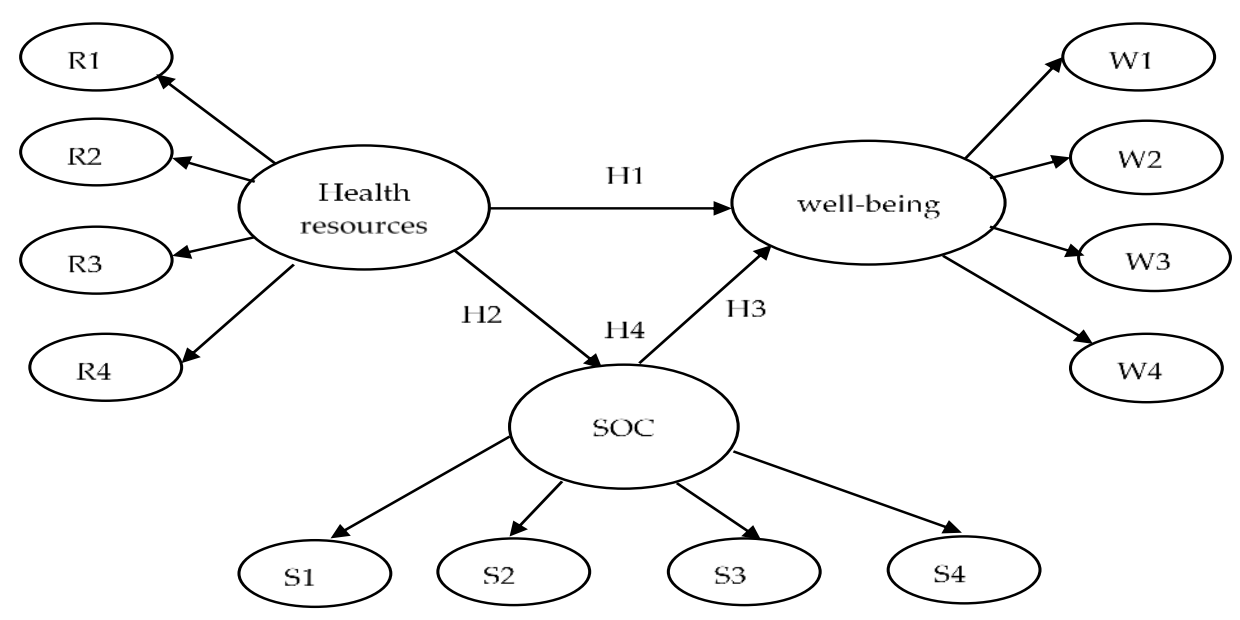

Figure 1. Research model. Note: R1 (Physical function), R2 (Mental function), R3 (Role), R4 (Social relations), S1 (Elective selection), S2 (Loss-selection), S3 (Optimization), S4 (Compensation), W1 (Physiology), W2 (Psychology), W3 (Society), W4 (Environment).

\section{Results}

\subsection{Reliability and Validity}

Confirmatory factor analysis for the measurement model to test reliability and validity results is shown in Table 1. The standardized factor loadings (SFL) of each sub-dimension ranged from 0.55 to 0.92 , and showed significance (critical ratio $>1.96, p<0.05$ ). All the measures had acceptable CR, since they ranged from 0.62 to 0.89 and exceeded 0.6 [55]. Most measures accounting for AVE were more than 0.5. The measurement model could explain a considerable proportion of the variance in reliability, convergent validity, and internal validity. Composite reliability (CR) and average variance extracted (AVE) were calculated to examine reliability and internal validity, that is, these constructs in the measurement model have reliability and internal validity. There are two criteria for convergence validity: the standardized factor load of each indicator is greater than 0.50 and significant; and average variance extracted (AVE) is greater than 0.50 , that is, these constructs in the measurement model have convergence validity.

In addition, discriminant validity was assessed between the constructs. When the square root of each AVE for the constructs was more significant than the correlation coefficient between other constructs, these constructs had discriminant validity [56]. Table 2 shows the result of discriminate validity. The square root of each AVE was in the range 0.671-0.897, which was greater than the correlation coefficient between dimensions, suggesting discriminate validity.

Table 2. Discriminate validity.

\begin{tabular}{|c|c|c|c|c|c|c|c|c|c|c|c|c|}
\hline & R1 & R2 & R3 & R4 & S1 & S2 & S3 & S4 & W1 & W2 & W3 & W4 \\
\hline R1 & 0.720 & & & & & & & & & & & \\
\hline R2 & $0.345^{* *}$ & 0.717 & & & & & & & & & & \\
\hline R3 & $0.641^{* *}$ & $0.356^{* *}$ & 0.718 & & & & & & & & & \\
\hline R4 & $0.567 * *$ & $0.429 * *$ & $0.655^{* *}$ & 0.897 & & & & & & & & \\
\hline S1 & $-0.136^{* *}$ & 0.030 & -0.111 * & $-0.126^{*}$ & 0.770 & & & & & & & \\
\hline S2 & 0.016 & 0.135 ** & -0.030 & 0.066 & $0.254 * *$ & 0.672 & & & & & & \\
\hline S3 & $0.173 * *$ & $0.280^{* *}$ & $0.205^{* *}$ & $0.216^{* *}$ & $0.231 * *$ & $0.187^{* *}$ & 0.751 & & & & & \\
\hline S4 & $0.134^{* *}$ & $0.247^{* *}$ & $0.189 * *$ & $0.149^{* *}$ & $0.230 * *$ & $0.172 * *$ & 0.610 ** & 0.671 & & & & \\
\hline W1 & $0.514^{* *}$ & $0.543 * *$ & $0.455^{* *}$ & 0.393 ** & 0.008 & $0.112 *$ & 0.320 ** & $0.297 * *$ & 0.727 & & & \\
\hline W2 & $0.416^{* *}$ & $0.677^{* *}$ & 0.400 ** & $0.412 * *$ & 0.102 & 0.146 ** & $0.337^{* *}$ & $0.307^{* *}$ & $0.634^{* *}$ & 0.731 & & \\
\hline W3 & $0.231 * *$ & $0.502 * *$ & $0.302 * *$ & $0.281^{* *}$ & $0.206^{* *}$ & $0.138^{* *}$ & $0.348^{* *}$ & $0.387 * *$ & $0.509^{* *}$ & $0.565^{* *}$ & 0.753 & \\
\hline W4 & $0.256^{* *}$ & $0.348^{* *}$ & $0.149 * *$ & $0.209 * *$ & 0.049 & 0.025 & $0.305^{* *}$ & $0.210^{* *}$ & $0.384^{* *}$ & 0.419 ** & $0.353^{* *}$ & 0.723 \\
\hline
\end{tabular}

The square root of AVE is in bold on the diagonal; and the others are correlation coefficients. ${ }^{*} p<0.05 ;{ }^{* *} p<0.01$. 


\subsection{Structural Model and Hypothesis Testing}

The model exhibits a good fit as follow: in terms of absolute fit index, the ratio of the chi-square value to the degree of freedom $(\chi 2 / \mathrm{df}<3)$, goodness-of-fit index $(\mathrm{GFI}>0.9)$, adjusted goodness-of-fit index (AGFI $>0.9$ ), root mean square error of approximation (RMSEA < 0.08) [57]; in terms of baseline comparisons, normed fit index (NFI > 0.9), nonnormed fit index (NNFI > 0.9), comparative fit index (CFI > 0.9), incremental fit index (IFI > 0.9) [58]; in terms of parsimony-adjusted measure, parsimonious normed fit index (PNFI > 0.50), parsimonious goodness-of-fit index (PGFI > 0.5). If large samples produce an oversized chi-square value, the ratio of the chi-square value to the degree of freedom should be used for judgment, and this ratio should be less than 3 [57].

The measurement model assumes a latent factor for each scale. Table 3 shows that the measurement model exhibited the goodness-of-fit indicators $\chi 2 / \mathrm{df}=2.035<3$; RMA $=0.039$, SRMR $=0.051<0.08 ;$ RMSEA $=0.053<0.08 ; \mathrm{NNFI}=0.901, \mathrm{CFI}=0.921$, $\mathrm{IFI}=0.923>0.9 ; \mathrm{PNFI}=0.680, \mathrm{PGFI}=0.657>0.5 ; \mathrm{CN}=205>200$. Other indicators GFI, AGFI, NFI, and RFI were close to the benchmarks. The measurement model results show that absolute fit index, baseline comparisons, and parsimony-adjusted measure meet the general academic requirements.

Table 3. Model fit results.

\begin{tabular}{ccccc}
\hline Indicators & & Threshold & Measurement Model & Structural Model \\
\hline Absolute fit index & $\chi 2$ ( $p$ value $)$ & $p$ value $>0.05$ & $748.759(0.000)$ & $59.743(0.000)$ \\
& $\chi 2 /$ df & $<3$ & 2.035 & 1.171 \\
& GFI & $>0.9$ & 0.885 & 0.976 \\
& AGFI & $>0.9$ & 0.845 & 0.964 \\
& RMR & $<0.08$ & 0.039 & 0.043 \\
& SRMR & $<0.08$ & 0.051 & 0.087 \\
& RMSEA & $<0.08$ & 0.053 & 0.021 \\
\hline Baseline comparisons & NFI & $>0.9$ & 0.859 & 0.964 \\
& NNFI & $>0.9$ & 0.901 & 0.993 \\
& CFI & $>0.9$ & 0.921 & 0.995 \\
& RFI & $>0.9$ & 0.822 & 0.954 \\
\hline IFI & $>0.9$ & 0.923 & 0.995 \\
\hline
\end{tabular}

The structural model further defines paths between the latent variables. The causal relationship between each construct was found, as shown in Figure 2 Path coefficients of the structural model. Employing the Bollen-Stine Bootstrap rather than Maximum likelihood tested the structural model fit. Table 3 shows that the structural model exhibited the goodness-of-fit indicators $\chi 2 / \mathrm{df}=1.171, \mathrm{GFI}=0.976$, AGFI $=0.964, \mathrm{RMA}=0.043$, $\mathrm{RMSEA}=0.021, \mathrm{NFI}=0.964, \mathrm{NNFI}=0.993, \mathrm{CFI}=0.995, \mathrm{RFI}=0.954, \mathrm{IFI}=0.995, \mathrm{PNFI}=0.74$, PGFI $=0.638, C N=427$, and SRMR $=0.087$ near the threshold 0.08 . The structural model results show that absolute fit index, baseline comparisons, and parsimony-adjusted measure meet the general academic requirements.

Table 4 illustrates the path coefficients for the structural model. Health resources were positively related to well-being $\left(\mathrm{r}=0.607^{* * *}, \mathrm{t}=7.761, p<0.000\right)$, which supported Hypothesis 1 . Health resources were also positively related to SOC strategies $(r=0.301 * * *$, $\mathrm{t}=4.475, p<0.000$ ), which supported Hypothesis 2 . SOC strategies were positively related to well-being $\left(\mathrm{r}=0.365^{* * *}, \mathrm{t}=5.737, p<0.000\right)$. Thus, Hypothesis 3 was supported. 


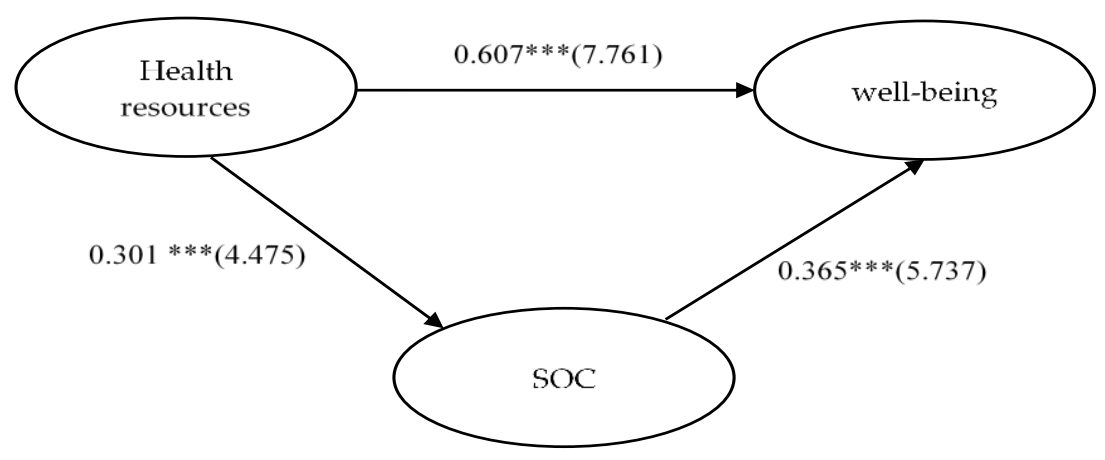

Figure 2. Path coefficients of the structural model. Note: Path Coefficients (t value) ${ }^{* *} p<0.001$.

Table 4. Path analysis.

\begin{tabular}{cccc}
\hline Variables Path & Path Coefficients & t Value & Hypothesis \\
\hline Health resources $\rightarrow$ well-being & $0.607^{* * *}$ & 7.761 & H1 supported \\
Health resources $\rightarrow$ SOC & $0.301^{* * *}$ & 4.475 & H2 supported \\
SOC $\rightarrow$ well-being & $0.365^{* * *}$ & 5.737 & H3 supported \\
\hline
\end{tabular}

$$
* * * p<0.001
$$

\subsection{Mediating Effects Analysis}

Bootstrapping was utilized to test mediation in Table 5. The indirect relationship between health resources and well-being via SOC was positive and statistically significant (indirect effect $=0.110$, bias-corrected percentile method under $95 \%$ confidence interval $(\mathrm{BC})=[0.057,0.174], p=0.001$; percentile method under $95 \%$ confidence interval $(\mathrm{PC})=$ $[0.054,0.171], p=0.001)$. Hypothesis 4 was supported. In addition, the direct relationship between health and well-being was positive and statistically significant (direct effect = $0.607, \mathrm{BC}=[0.480,0.725], p=0.001 ; \mathrm{PC}=[0.480,0.726], p=0.001)$. The direct relationship between health and SOC was positive and statistically significant (direct effect $=0.301, \mathrm{BC}$ $=[0.137,0.432], p=0.001 ; \mathrm{PC}=[0.146,0.439], p=0.001)$. The direct relationship between SOC and well-being was positive and statistically significant (direct effect $=0.365, \mathrm{BC}=$ $[0.224,0.483], p=0.001 ; \mathrm{PC}=[0.232,0.490], p=0.001)$. The total effect among health, SOC, and well-being was positive and statistically significant (total effect $=0.717, \mathrm{BC}=[0.603$, $0.814], p=0.001 ; \mathrm{PC}=[0.606,0.819], p=0.001)$. As the ratio of indirect effect to total effect $=$ 0.153 , SOC was a partial mediator between health and well-being.

Table 5. Mediating Effect and Bootstrapping.

\begin{tabular}{|c|c|c|c|c|}
\hline & Effect & BC/PC $p$ Value & $\begin{array}{c}95 \% \text { CI } \\
\text { BC }\end{array}$ & $\begin{array}{c}95 \% \text { CI } \\
\text { PC }\end{array}$ \\
\hline $\begin{array}{c}\text { Indirect effect } \\
\text { Health } \\
\text { resources } \rightarrow \text { SOC } \rightarrow \text { well-being }\end{array}$ & 0.110 & $0.001 / 0.001$ & $0.057 \sim 0.174$ & $0.054 \sim 0.171$ \\
\hline $\begin{array}{c}\text { Direct effect } \\
\text { Health resources } \rightarrow \text { SOC } \\
\text { SOC } \rightarrow \text { well-being } \\
\text { Health resources } \rightarrow \text { well-being }\end{array}$ & $\begin{array}{l}0.301 \\
0.365 \\
0.607\end{array}$ & $\begin{array}{l}0.001 / 0.001 \\
0.001 / 0.001 \\
0.001 / 0.001\end{array}$ & $\begin{array}{l}0.137 \sim 0.432 \\
0.224 \sim 0.483 \\
0.480 \sim 0.725\end{array}$ & $\begin{array}{l}0.146 \sim 0.439 \\
0.232 \sim 0.490 \\
0.480 \sim 0.726\end{array}$ \\
\hline Total effect & 0.717 & $0.001 / 0.001$ & $0.603 \sim 0.814$ & $0.606 \sim 0.819$ \\
\hline
\end{tabular}

\subsection{Group Analysis}

Group analysis is to calculate demographic variables, including gender, age, marriage, children, education, job, income, and religion. The results are shown as Table 6. All of the eight control variables show no significant difference between the fully free and fully 
fixed model, such as gender $\left(\Delta \chi^{2}=5.034, \Delta \mathrm{df}=3, p=0.169\right)$, age $\left(\Delta \chi^{2}=1.652, \Delta \mathrm{df}=6\right.$, $p=0.949)$, marriage $\left(\Delta \chi^{2}=5.480, \Delta \mathrm{df}=3, p=0.140\right)$, children $\left(\Delta \chi^{2}=1.694, \Delta \mathrm{df}=3\right.$, $p=0.638)$, education $\left(\Delta \chi^{2}=3.958, \Delta \mathrm{df}=3, p=0.266\right)$, job $\left(\Delta \chi^{2}=2.478, \Delta \mathrm{df}=3, p=0.479\right)$, income $\left(\Delta \chi^{2}=4.246, \Delta \mathrm{df}=3, p=0.236\right)$, and religion $\left(\Delta \chi^{2}=4.537, \Delta \mathrm{df}=3, p=0.209\right)$. Therefore, the relationship between health resources and well-being is mediated by SOC strategies under control variables.

Table 6. Group analysis.

\begin{tabular}{cccccc}
\hline Control Variables & $\chi^{\mathbf{2}}$ & & $\boldsymbol{\Delta} \boldsymbol{\chi}^{\mathbf{2}}$ & $\boldsymbol{\Delta} \mathbf{d f}$ & $\boldsymbol{p}$ \\
\hline & Free Model & Fixed Model & & & \\
\hline Gender & 357.517 & 362.550 & 5.034 & 3 & 0.169 \\
Age & 437.618 & 439.270 & 1.652 & 6 & 0.949 \\
Marriage & 366.768 & 372.247 & 5.480 & 3 & 0.140 \\
Children & 364.978 & 366.672 & 1.694 & 3 & 0.638 \\
Education & 355.406 & 359.364 & 3.958 & 3 & 0.266 \\
Job & 337.308 & 339.786 & 2.478 & 3 & 0.479 \\
Income & 344.240 & 348.486 & 4.246 & 3 & 0.236 \\
Religion & 356.443 & 360.980 & 4.537 & 3 & 0.209 \\
\hline
\end{tabular}

\section{Discussion}

The most original finding of our research was that the use of SOC strategy could play a meaningful mediating role between the context resources of health-related functions and the sense of well-being. The mediation effects that were noticed give insight into the coping processes by means of which health resources might have an impact on the well-being of individuals. However, we further identified several studies that investigated the use of SOC strategies as a mediator or moderator of the relationship between context antecedents and outcomes. Previous studies $[13,59,60]$ proposed that SOC strategies act as mediators. Nevertheless, there is evidence [61-64] that the use of SOC could also serve as a meaningful buffer (moderator). We assumed that using SOC strategies acts as a mediator between health resources and well-being and found empirical confirmation within the 372 surveyed middle-aged and elderly samples. Hence, our research contributes to the growing evidence.

Compared with people with abundant health resources, the use of SOC strategies for people with health problems seemed to have less effect on well-being. Our findings were consistent with SOC theory and COR theory. When old employees effectively used limited personal resources through SOC, they could still complete the job requirements [33]. Moreover, employees with more resources at work were more capable of using their own coping strategies to maximize work-related resources and create favorable working conditions for individuals $[65,66]$. Some studies addressed health, well-being, or SOC, but there was less discussion on the combination of the three variables. Our findings contribute to establishing a model of connections with health resources, SOC use, and well-being, and emphasize the mediating role of SOC in explaining individual behavior.

\subsection{Implications}

The findings of this study have research and practical implications. This study pointed out the steps of establishing SOC strategies as an optimal aging construct by demonstrating that health resources were positively associated with SOC strategies as well as well-being, and that SOC strategies mediated the positive impact of health resources on well-being. In line with the previous studies $[39,40]$, our results showed the fact that health resources were positively related to well-being. Our findings were also consistent with studies that showed that health resources were positively related to SOC strategies [44,67]. In addition, Varianou-Mikellidou et al. [68] indicated that health status might be one of the main factors affecting work ability in all age groups. The studies showed that the remainder of individual work ability with aging was viewed as one part of human capital resources in an 
organization [21,69]. Thus, related health was considered an integral part of the resources available to individuals in working, coping with life challenges and promoting well-being.

In addition, the findings demonstrated that the issue of occupational health and aging might be identified as productivity at the organization level as well [70,71]. Even though the aging workforce impacted the organizational bottom line, this effect of using SOC strategies was mediated through the resources of physical and mental functions. Similar results $[15,45]$ were found, where using SOC strategies might be more capable of adapting to change the age-related resource loss and maintain resources to reach required performance and well-being. Furthermore, by examining the effects of SOC strategies in individual, family, work, and society, this study also supported the implications of the SOC literature and aging research. Previous research has mainly examined SOC use at the individual level [22] and has also moved this concept to the workplace collective level. [21]. In order to counter the potential effect of aging on health resources and wellbeing, human resource management policies and practices (e g., career development, friendly environment) could encourage adults to use SOC strategies in daily life.

\subsection{Limitations and Directions for Future Research}

This study has several limitations. First, the study was potentially limited by crosssectional data collection instead of longitudinal design. Adults could use SOC strategies to help maintain well-being with different stages [13]. Previous research showed that the elderly decreased health resources more quickly after they reached retirement age [72] Given the cross-sectional design of the current study, we cannot rule out the possibility of reversed causation between health resources and SOC strategies. Future research should design longitudinal cohort sequential studies to measure these variables over time.

Another possible limitation was the age of the sample in our study, which was divided into three age groups (45-54 years old, 55-64 years old, and 65 years or older). These ranges were too large to calculate the change in age. Thus, it was difficult to predict the average age of people using SOC strategies (i.e., health resources, well-being) in a linear or nonlinear relationship [21]. Future research should consider age variables to predict changes and reversal points.

Third, the environmental areas of the samples were not collected in our study. Previous research indicated that an age-friendly environment, such as elderly-friendly outdoor spaces, healthcare services, and public transportation, had a positive and statistically significant relationship with active aging [73]. Future research could consider relevant indicators of environmental regions to extend the issue. In addition, based on occupational health, it should take the ongoing attrition of organizational employees due to aging into consideration in certain industries or compared with several units. Following the two variables between SOC strategies and workplace satisfaction, future research should test aging-related HRM policies and practices on the basis of existing empirical and theoretical evidence.

Another possible extension of the current research is to examine the mediating weights of elective selection, loss-based selection, optimization, and compensation among SOC strategies. This would provide new information on the complex relationship between resources and well-being measures. We also call for further studies to design qualitative research, such as case studies and narrative inquiry, to understand how resources, SOC strategies, and well-being are formed to face aging and how to survive in tough conditions. By increasing the measurement index, future research should examine whether these variables of optimal aging predict their well-being.

\section{Conclusions}

The SOC's strategy to cope with age-related changes was essential to actively allocate resources to well-being. This survey aimed to elucidate the interplay between health resources and personal management strategies in selection, optimization, and compensation to determine well-being status. As hypothesized, we found that people who used more 
SOC strategies or had high health resources perceived better well-being. We also found that people who had high health resources used more SOC strategies. Health resources could help people through the use of SOC strategies to maintain their well-being. Drawing on a sample of middle-aged and older people, our study revealed a meaningful indirect effect of health on well-being mediated through SOC use.

Author Contributions: Conceptualization, C.-H.W. and F.-F.T.; methodology, C.-H.W. and F.-F.T.; software, F.-F.T.; validation, C.-H.W. and F.-F.T.; formal analysis, C.-H.W. and F.-F.T.; investigation, C.-H.W. and F.-F.T.; data curation, F.-F.T.; writing—original draft preparation, F.-F.T.; writing—review and editing, C.-H.W. and F.-F.T.; supervision, C.-H.W.; project administration, F.-F.T. All authors have read and agreed to the published version of the manuscript.

Funding: This research received no external funding.

Institutional Review Board Statement: Not applicable.

Informed Consent Statement: Not applicable.

Data Availability Statement: Not applicable.

Conflicts of Interest: The authors declare no conflict of interest.

\section{Appendix A}

Table A1. Questionnaire items in measurement scales.

\begin{tabular}{|c|c|c|c|}
\hline Dimension & Code & Sub-Dimension & Item Content \\
\hline \multirow{4}{*}{ Health resources } & $\mathrm{R} 1$ & Physical function & $\begin{array}{l}\text { 1. Compared to one year ago, you would rate your } \\
\text { health to become worse in general now. } \\
\text { 2. Your health now limits you in these activities such as } \\
\text { moving a table and climbing flights of stairs. } \\
\text { 3. You often have had bodily pain. }\end{array}$ \\
\hline & $\mathrm{R} 2$ & Mental function & $\begin{array}{l}\text { 4. You often have felt calm and peaceful. } \\
\text { 5. You often have felt downhearted and blue. } \\
\text { 6. You have been a happy person. }\end{array}$ \\
\hline & R3 & Role & $\begin{array}{l}\text { 7. You have had any of the following problems with } \\
\text { your work or other regular daily activities as a result } \\
\text { of your physical health or any emotional problems: } \\
\text { Cut down the amount of time you spent on work or } \\
\text { other activities. } \\
\text { 8. You have had any of the following problems with } \\
\text { your work or other regular daily activities as a result } \\
\text { of your physical health or any emotional problems: } \\
\text { Accomplished less than you would like. } \\
\text { You have had any of the following problems with } \\
\text { your work or other regular daily activities as a result } \\
\text { of your physical health or any emotional problems: } \\
\text { Were limited in the kind of work or other activities. }\end{array}$ \\
\hline & $\mathrm{R} 4$ & Social relations & $\begin{array}{l}\text { 10. How much of the time your physical health or } \\
\text { emotional problems has interfered with your social } \\
\text { activities (like visiting with friends, relatives, etc.). } \\
\text { 11. To what extent your physical health or emotional } \\
\text { problems has interfered with your normal social } \\
\text { activities with family, friends, neighbors, or groups. }\end{array}$ \\
\hline
\end{tabular}


Table A1. Cont.

\begin{tabular}{|c|c|c|c|}
\hline Dimension & Code & Sub-Dimension & Item Content \\
\hline \multirow{4}{*}{ SOC } & S1 & Elective selection & $\begin{array}{l}\text { 1. I always focus on the one most important goal at a } \\
\text { given time. } \\
\text { 2. I commit myself to one or two important goals. }\end{array}$ \\
\hline & S2 & Loss-selection & $\begin{array}{l}\text { 3. When I can't do something important at work the way } \\
\text { I did before, I look for a new goal. } \\
\text { 4. When I can't do something at work as well as I used } \\
\text { to, I think about my priorities and what exactly is } \\
\text { important to me. }\end{array}$ \\
\hline & S3 & Optimization & $\begin{array}{l}\text { 5. At work, I make every effort to achieve a given goal. } \\
\text { 6. If something matters to me at work, I devote myself } \\
\text { fully and completely to it. }\end{array}$ \\
\hline & S4 & Compensation & $\begin{array}{l}\text { 7. When things don't go as well as they used to, I keep } \\
\text { trying other ways until I can achieve the same result I } \\
\text { used to. } \\
\text { 8. When something at work isn't working as well as it } \\
\text { used to, I ask others for advice or help. } \\
\text { 9. When it becomes harder for me to get the same results } \\
\text { at work, I keep trying harder until I can do it as well } \\
\text { as before. }\end{array}$ \\
\hline \multirow{4}{*}{ Well-being } & W1 & Physiology & $\begin{array}{l}\text { 1. You are satisfied with your health. } \\
\text { 2. You are satisfied with your sleep. } \\
\text { 3. You are satisfied with your ability to perform your } \\
\text { daily living activities. }\end{array}$ \\
\hline & W2 & Psychology & $\begin{array}{l}\text { 4. You enjoy life. } \\
\text { 5. You feel your life to be meaningful. } \\
\text { 6. You often have negative feelings such as blue mood, } \\
\text { despair, anxiety, depression. }\end{array}$ \\
\hline & W3 & Society & $\begin{array}{l}\text { 7. You are satisfied with your personal relationships. } \\
\text { 8. You are satisfied with the support you get from your } \\
\text { friends. } \\
\text { 9. You feel respected. }\end{array}$ \\
\hline & W4 & Environment & $\begin{array}{l}\text { 10. You are satisfied with the convenience of your daily } \\
\text { life, such as health services, shopping, transportation, } \\
\text { sports, meals, etc. } \\
\text { 11. You are satisfied with the conditions of your } \\
\text { living place. }\end{array}$ \\
\hline
\end{tabular}

\section{References}

1. Cooke, F.L.; Dickmann, M.; Parry, E. Important Issues in Human Resource Management: Introduction to the 2020 Review Issue. Int. J. Hum. Resour. 2020, 31, 1-5. [CrossRef]

2. Sahu, P. Closure of Universities Due to Coronavirus Disease 2019 (COVID-19): Impact on Education and Mental Health of Students and Academic Staff. Cureus 2020, 12, e7541. [CrossRef] [PubMed]

3. Zabaniotou, A.A. Systemic Approach to Resilience and Ecological Sustainability during the COVID-19 Pandemic: Human, Societal, and Ecological Health as a System-wide Emergent Property in the Anthropocene. Glob. Transit. 2020, 2, 116-126. [CrossRef] [PubMed]

4. Sentell, T.; Vamos, S.; Okan, O. Interdisciplinary Perspectives on Health Literacy Research around the World: More Important than ever in a Time of COVID-19. Int. J. Environ. Res. Public Health 2020, 17, 3010. [CrossRef] [PubMed]

5. Niu, S.; Tian, S.; Lou, J.; Kang, X.; Zhang, L.; Lian, H.; Zhang, J. Clinical Characteristics of Older Patients Infected with COVID-19: A Descriptive Study. Arch. Gerontol. Geriatr. 2020, 89, 104058. [CrossRef] [PubMed]

6. Singer, L.; Green, M.; Rowe, F.; Ben-Shlomo, Y.; Morrissey, K. Social Determinants of Multimorbidity and Multiple Functional Limitations among the Ageing Population of England, 2002-2015. SSM Popul. Health 2019, 8, 100413. [CrossRef]

7. Fingerman, K.L.; Huo, M.; Birditt, K.S. A Decade of Research on Intergenerational Ties: Technological, Economic, Political, and Demographic Changes. J. Marriage Fam. 2020, 82, 383-403. [CrossRef] 
8. Allegrante, J.P.; Wells, M.T.; Peterson, J.C. Interventions to Support Behavioral Self-management of Chronic Diseases. Annu. Rev. Public Health 2019, 40, 127-146. [CrossRef]

9. Burn, I.; Button, P.; Figinski, T.F.; McLaughlin, J.S. Why Retirement, Social Security, and Age Discrimination Policies Need to Consider the Intersectional Experiences of Older Women. Public Policy Aging Rep. 2020, 30, 101-106. [CrossRef]

10. Boissonneault, M.; Mulders, J.O.; Turek, K.; Carriere, Y. A Systematic Review of Causes of Recent Increases in Ages of Labor Market Exit in OECD Countries. PLoS ONE 2020, 15, e231897. [CrossRef]

11. Atella, V.; Mortari, A.P.; Kopinska, J.; Belotti, F.; Lapi, F.; Cricelli, C.; Fontana, L. Trends in Age-Related Disease Burden and Healthcare Utilization. Aging Cell 2019, 18, e12861. [CrossRef]

12. Gebremariam, K.M.; Sadana, R. On the Ethics of Healthy Ageing: Setting Impermissible Trade-Offs Relating to the Health and Well-Being of Older Adults on the Path to Universal Health Coverage. Int. J. Equity Health 2019, 18, 1-16. [CrossRef]

13. Carpentieri, J.D.; Elliott, J.; Brett, C.E.; Deary, I.J. Adapting to Aging: Older People Talk about Their Use of Selection, Optimization, and Compensation to Maximize Well-being in the Context of Physical Decline. J. Gerontol. Ser. B 2017, 72, 351-361. [CrossRef]

14. Galiana, L.; Tomás, J.M.; Fernández, I.; Oliver, A. Predicting Well-Being Among the Elderly: The Role of Coping Strategies. Front. Psychol. 2020, 11, 616. [CrossRef] [PubMed]

15. Müller, A.; Heiden, B.; Herbig, B.; Poppe, F.; Angerer, P. Improving Well-being at Work: A Randomized Controlled Intervention Based on Selection, Optimization, and Compensation. J. Occup. Health Psychol. 2016, 21, 169-181. [CrossRef] [PubMed]

16. Chopik, W.J. Associations among Relational Values, Support, Health, and Well-being across the Adult Lifespan. Pers. Relatsh. 2017, 24, 408-422. [CrossRef]

17. Zhang, W.; Radhakrishnan, K. Evidence on Selection, Optimization, and Compensation Strategies to Optimize Aging with Multiple Chronic Conditions: A Literature Review. Geriatr. Nurs. 2018, 39, 534-542. [CrossRef]

18. Knecht, M.; Freund, A.M. The Use of Selection, Optimization, and Compensation (SOC) in Goal Pursuit in the Daily Lives of Middle-aged Adults. Eur. J. Dev. Psychol. 2017, 14, 350-366. [CrossRef]

19. Hobfoll, S.E.; Halbesleben, J.; Neveu, J.P.; Westman, M. Conservation of Resources in the Organizational Context: The Reality of Resources and their Consequences. Annu. Rev. Organ. Psychol. Organ. Behav. 2018, 5, 103-128. [CrossRef]

20. Halbesleben, J.R.B.; Neveu, J.-P.; Paustian-Underdahl, S.C.; Westman, M. Getting to the "COR": Understanding the Role of Resources in Conservation of Resources Theory. J. Manag. 2014, 40, 1334-1364. [CrossRef]

21. Von Bonsdorff, M.E.; Zhou, L.; Wang, M.; Vanhala, S.; von Bonsdorff, M.B.; Rantanen, T. Employee Age and Company Performance: An Integrated Model of Aging and Human Resource Management Practices. J. Manag. 2018, 44, 3124-3150. [CrossRef]

22. Moghimi, D.; Zacher, H.; Scheibe, S.; Van Yperen, N.W. The Selection, Optimization, and Compensation Model in the Work Context: A Systematic Review and Meta-analysis of Two Decades of Research. J. Organ. Behav. 2017, 38, 247-275. [CrossRef]

23. Aldwin, C.M.; Igarashi, H. Models of Successful, Resilient, and Optimal Aging. In Health, Illness, and Optimal Aging: Biological and Psychosocial Perspectives, 3rd ed.; Aldwin, C.M., Igarashi, H., Gilmer, D.F., Levenson, M.R., Eds.; Springer: New York, NY, USA, 2016; pp. 377-385.

24. Cooper, D.K.; Wieling, E.; Pfeiffer, A. Bioecological Implications of Narrative Exposure Therapy in Low-resource Settings: Individual, Family, Community, and Socio-political Contexts. Aust. N. Z. J. Fam. Ther. 2019, 40, 353-367. [CrossRef]

25. Baumann, D.; Ruch, W.; Margelisch, K.; Gander, F.; Wagner, L. Character Strengths and Life Satisfaction in Later Life: An Analysis of Different Living Conditions. Appl. Res. Qual. Life 2020, 15, 329-347. [CrossRef]

26. Derdaele, E.; Toussaint, L.; Thauvoye, E.; Dezutter, J. Forgiveness and Late Life Functioning: The Mediating Role of Finding Ego-integrity. Aging Ment. Health 2019, 23, 238-245. [CrossRef] [PubMed]

27. Satorres, E.; Viguer, P.; Fortuna, F.B.; Meléndez, J.C. Effectiveness of Instrumental Reminiscence Intervention on Improving Coping in Healthy Older Adults. Stress Health 2018, 34, 227-234. [CrossRef] [PubMed]

28. Hobfoll, S.E. Conservation of Resources. A New Attempt at Conceptualizing Stress. Am. Psychol. 1989, 44, 513-524. [CrossRef]

29. Park, Y.; Fritz, C.; Jex, S.M. Daily Cyber Incivility and Distress: The Moderating Roles of Resources at Work and Home. J. Manag. 2018, 44, 2535-2557. [CrossRef]

30. Gilbert, E.; Foulk, T.; Bono, J. Building Personal Resources through Interventions: An Integrative Review. J. Organ. Behav. 2018, 39, 214-228. [CrossRef]

31. Jung, H.W.; Jang, I.Y.; Lee, Y.S.; Lee, C.K.; Cho, E.I.; Kang, W.Y.; Chae, J.H.; Kim, D.H. Prevalence of Frailty and Aging-related Health Conditions in Older Koreans in Rural Communities: A Cross-sectional Analysis of the Aging Study of Pyeongchang Rural Area. J. Korean Med. Sci. 2016, 31, 345-352. [CrossRef]

32. Rowe, A.K.; Rowe, S.Y.; Peters, D.H.; Holloway, K.A.; Chalker, J.; Ross-Degnan, D. Effectiveness of Strategies to Improve Health-care Provider Practices in Low-income and Middle-income Countries: A Systematic Review. Lancet Glob. Health 2018, 6, e1163-e1175. [CrossRef]

33. Sottimano, I.; Guidetti, G.; Viotti, S.; Converso, D. The Interplay between Job Control, SOC Strategies, and Age in Sustaining Work Ability in a Sample of administrative employees. Sustainability 2019, 11, 1463. [CrossRef]

34. Kooij, D.T.; Nijssen, H.; Bal, P.M.; van der Kruijssen, D.T. Crafting an Interesting Job: Stimulating an Active Role of Older Workers in Enhancing their Daily Work Engagement and Job Performance. Work. Aging Retire. 2020, 6, 165-174. [CrossRef]

35. Han, S.Y.; Ko, Y.A. Structural Equation Model of Successful Aging in Korean Older Women: Using Selection-OptimizationCompensation (SOC) Strategies. J. Women Aging 2019, 33, 1-16. [CrossRef] 
36. Freund, A.M.; Napolitano, C.M.; Knecht, M. Life Management through Selection, Optimization, and Compensation. Encycl. Geropsychol. 2017, 1389-1397. [CrossRef]

37. Venz, L.; Pundt, A.; Sonnentag, S. What Matters for Work Engagement? A Diary Study on Resources and the Benefits of Selective Optimization with Compensation for State Work Engagement. J. Organ. Behav. 2018, 39, 26-38. [CrossRef]

38. Ho, H.; Kuvaas, B. Human Resource Management Systems, employee Well-being, and Firm Performance from the Mutual Gains and Critical Perspectives: The Well-being Paradox. Hum. Resour. Manag. 2020, 59, 235-253. [CrossRef]

39. Ngamaba, K.H.; Panagioti, M.; Armitage, C.J. How Strongly Related are Health Status and Subjective Well-being? Systematic Review and Meta-analysis. Eur. J. Public Health 2017, 27, 879-885. [CrossRef]

40. Sun, S.; Chen, J.; Johannesson, M.; Kind, P.; Burström, K. Subjective Well-being and its Association with Subjective Health Status, Age, Sex, Region, and Socio-economic Characteristics in a Chinese Population Study. J. Happiness Stud. 2016, 17, 833-873. [CrossRef]

41. Steptoe, A. Happiness and Health. Annu. Rev. Public Health 2019, 40, 339-359. [CrossRef]

42. Weber, J.; Müller, A.; Stiller, M.; Borchart, D. Prognostic Effects of Selection, Optimization and Compensation Strategies on Work Ability: Results from the Representative LidA Cohort Study on Work, Age, and Health in Germany. Int. Arch. Occup. Environ. Health 2018, 91, 1061-1071. [CrossRef] [PubMed]

43. Zacher, H. Successful Ageing at Work. Work. Aging Retire. 2015, 1, 4-25. [CrossRef]

44. Shang, L.; Riedel, N.; Loerbroks, A.; Müller, A.; Wege, N.; Angerer, P.; Li, J. The Association between Effort-reward Imbalance and Depressive Symptoms is Modified by Selection, Optimization, and Compensation Strategy. J. Occup. Environ. Med. 2015, 57, 1222-1227. [CrossRef]

45. Joly-Burra, E.; Van der Linden, M.; Ghisletta, P. A Mixed-method Study on Strategies in Everyday Personal Goals among Community-dwelling Older Adults. Gerontology 2020, 66, 1-10. [CrossRef]

46. Baltes, P.B. On the Incomplete Architecture of Human Ontogeny: Selection, Optimization, and Compensation as Foundation of Developmental Theory. Am. Psychol. 1997, 52, 366-380. [CrossRef]

47. Cho, J.; Martin, P.; Poon, L.W. Successful Aging and Subjective Well-being among Oldest-old Adults. Gerontologist 2015, 55, 132-143. [CrossRef]

48. Potočnik, K.; Sonnentag, S. A longitudinal Study of Well-being in Older Workers and Retirees: The Role of Engaging in Different Types of Activities. J. Occup. Organ. Psychol. 2013, 86, 497-521. [CrossRef]

49. Ware, J.; Sherbourne, C. The MOS 36-Item Short-Form Health Survey (SF-36): I. Conceptual Framework and Item Selection. Med. Care 1992, 30, 473-483. Available online: https:/ / www.jstor.org/stable/3765916 (accessed on 22 March 2021). [CrossRef] [PubMed]

50. Gandek, B.; Ware, J.E.; Aaronson, N.K.; Apolone, G.; Bjorner, J.B.; Brazier, J.E.; Bullinger, M.; Kaasa, S.; Leplege, A.; Prieto, L.; et al. Cross-Validation of Item Selection and Scoring for the SF-12 Health Survey in Nine Countries. J. Clin. Epidemiol. 1998, 51, 1171-1178. [CrossRef]

51. Yao, G.; Chung, C.W.; Yu, C.F.; Wang, J.D. Development and Verification of Validity and Reliability of the WHOQOL-BREF Taiwan Version. J. Formos. Med. Assoc. 2002, 101, 342-351.

52. Whoqol Group. Development of the World Health Organization WHOQOL-BREF Quality of Life Assessment. Psychol. Med. 1998, 28, 551-558. [CrossRef]

53. Zacher, H.; Frese, M. Maintaining a Focus on Opportunities at Work: The Interplay between Age, Job Complexity, and the Use of Selection, Optimization, and Compensation Strategies. J. Organ. Behav. 2011, 32, 291-318. [CrossRef]

54. Ziegelmann, J.P.; Lippke, S. Planning and Strategy Use in Health Behavior Change: A Life Span View. Int. J. Behav. Med. 2007, 14, 30-39. [CrossRef]

55. Wu, T.Y.; Lin, C.Y.; Årestedt, K.; Griffiths, M.D.; Broström, A.; Pakpour, A.H. Psychometric Validation of the Persian Nine-item Internet Gaming Disorder Scale-Short Form: Does Gender and Hours Spent Online Gaming Affect the Interpretations of Item Descriptions? J. Behav. Addict. 2017, 6, 256-263. [CrossRef]

56. Fornell, C.; Larcker, D.F. Evaluating structural equation models with unobservable variables and measurement error. J. Mark. Res. 1981, 18, 39-50. [CrossRef]

57. Hair, J.F., Jr.; Babin, B.J.; Krey, N. Covariance-based structural equation modeling in the Journal of Advertising: Review and recommendations. J. Advert. 2017, 46, 163-177. [CrossRef]

58. Bagozzi, R.P.; Yi, Y. On the evaluation of structural equation models. J. Acad. Mark. Sci. 1988, 16, 74-94. [CrossRef]

59. Breevaart, K.; Zacher, H. Daily Selection, Optimization, and Compensation Strategy Use and Innovative Performance: The Role of Job Autonomy and Time Pressure. J. Pers. Psychol. 2019, 18, 71-83. [CrossRef]

60. Von Bonsdorff, M.E.; von Bonsdorff, M.B.; Zhou, Z.E.; Kauppinen, M.; Miettinen, M.; Rantanen, T.; Vanhala, S. Organizational Justice, Selection, Optimization with Compensation, and Nurses' Work Ability. J. Occup. Environ. Med. 2014, 56, 326-330. [CrossRef]

61. Baethge, A.; Müller, A.; Rigotti, T. Nursing Performance under High Workload: A Diary Study on the Moderating Role of Selection, Optimization and Compensation Strategies. J. Adv. Nurs. 2016, 72, 545-557. [CrossRef]

62. Segura-Camacho, A.; García-Orozco, J.J.; Topa, G. Sustainable and Healthy Organizations Promote Employee Well-being: The Moderating Role of Selection, Optimization, and Compensation Strategies. Sustainability 2018, 10, 3411. [CrossRef] 
63. Venz, L.; Sonnentag, S. Being Engaged When Resources are Low: A Multi-source Study of Selective Optimization with Compensation at Work. J. Vocat. Behav. 2015, 91, 97-105. [CrossRef]

64. Weigl, M.; Müller, A.; Hornung, S.; Zacher, H.; Angerer, P. The Moderating Effects of Job Control and Selection, Optimization, and Compensation Strategies on the Age-Work Ability Relationship. J. Organ. Behav. 2013, 34, 607-628. [CrossRef]

65. Van den Brande, W.; Baillien, E.; De Witte, H.; Vander Elst, T.; Godderis, L. The Role of Work Stressors, Coping Strategies and Coping Resources in the Process of Workplace Bullying: A Systematic Review and Development of a Comprehensive Model. Aggress. Violent Behav. 2016, 29, 61-71. [CrossRef]

66. Weigl, M.; Hornung, S.; Parker, S.K.; Petru, R.; Glaser, J.; Angerer, P. Work Engagement Accumulation of Task, Social, Personal Resources: A Three-wave Structural Equation Model. J. Vocat. Behav. 2010, 77, 140-153. [CrossRef]

67. Riedel, N.; Müller, A.; Ebner, M. Applying Strategies of Selection, Optimization, and Compensation to Maintain Work Ability-A Psychosocial Resource Complementing the Job Demand-Control Model? Results from the Representative lidA Cohort Study on Work, Age, and Health in Germany. J. Occup. Environ. Med. 2015, 57, 552-561. [CrossRef] [PubMed]

68. Varianou-Mikellidou, C.; Boustras, G.; Nicolaidou, O.; Dimopoulos, C.; Anyfantis, I.; Messios, P. Work-related Factors and Individual Characteristics Affecting Work Ability of Different Age Groups. Saf. Sci. 2020, 128, 104755. [CrossRef]

69. Ployhart, R.E.; Moliterno, T.P. Emergence of the Human Capital Resource: A Multilevel Model. Acad. Manag. Rev. 2011, 36, 127-150. [CrossRef]

70. McGonagle, A.K.; Fisher, G.G.; Barnes-Farrell, J.L.; Grosch, J.W. Individual and Work Factors Related to Perceived Work Ability and Labor Force Outcomes. J. Appl. Psychol. 2015, 100, 376-398. [CrossRef]

71. Varianou-Mikellidou, C.; Boustras, G.; Dimopoulos, C.; Wybo, J.L.; Guldenmund, F.W.; Nicolaidou, O.; Anyfantis, I. Occupational Health and Safety Management in the Context of an Ageing Workforce. Saf. Sci. 2019, 116, 231-244. [CrossRef]

72. Wu, C.; Odden, M.C.; Fisher, G.G.; Stawski, R.S. Association of Retirement Age with Mortality: A Population-based Longitudinal Study among Older Adults in the USA. J. Epidemiol. Community Health 2016, 70, 917-923. [CrossRef] [PubMed]

73. Lai, M.M.; Lein, S.Y.; Lau, S.H.; Lai, M.L. Modeling Age-friendly Environment, Active Aging, and Social Connectedness in an Emerging Asian Economy. J. Aging Res. 2016, 2016, 1-14. [CrossRef] [PubMed] 